\title{
Technology Acceptance of Augmented Reality and Wearable Technologies
}

Citation for published version (APA):

Wild, F., Klemke, R., Lefrere, P., Fominykh, M., \& Kuula, T. (2017). Technology Acceptance of Augmented Reality and Wearable Technologies. In D. B., C. A., L. M., J. P., F. K., J. R., \& C. G. (Eds.), Immersive Learning Research Network: Third International Conference, iLRN 2017, Coimbra, Portugal, June 26-29, 2017. Proceedings (pp. 129-141). Springer. Communications in Computer and Information Science Vol. 725 https://doi.org/10.1007/978-3-319-60633-0_11

\section{DOI:}

10.1007/978-3-319-60633-0_11

Document status and date:

Published: 01/01/2017

Document Version:

Peer reviewed version

\section{Document license:}

CC BY-NC-SA

Please check the document version of this publication:

- A submitted manuscript is the version of the article upon submission and before peer-review. There can be important differences between the submitted version and the official published version of record. People interested in the research are advised to contact the author for the final version of the publication, or visit the DOI to the publisher's website.

- The final author version and the galley proof are versions of the publication after peer review.

- The final published version features the final layout of the paper including the volume, issue and page numbers.

Link to publication

\section{General rights}

Copyright and moral rights for the publications made accessible in the public portal are retained by the authors and/or other copyright owners and it is a condition of accessing publications that users recognise and abide by the legal requirements associated with these rights.

- Users may download and print one copy of any publication from the public portal for the purpose of private study or research.

- You may not further distribute the material or use it for any profit-making activity or commercial gain

- You may freely distribute the URL identifying the publication in the public portal.

If the publication is distributed under the terms of Article 25fa of the Dutch Copyright Act, indicated by the "Taverne" license above, please follow below link for the End User Agreement:

https://www.ou.nl/taverne-agreement

Take down policy

If you believe that this document breaches copyright please contact us at:

pure-support@ou.nl

providing details and we will investigate your claim.

Downloaded from https://research.ou.nl/ on date: 26 Apr. 2023 


\title{
Technology Acceptance of Augmented Reality and Wearable Technologies
}

\author{
Fridolin Wild $^{1}$, Roland Klemke ${ }^{2}$, Paul Lefrere ${ }^{3}$, \\ Mikhail Fominykh ${ }^{4}$, and Timo Kuula ${ }^{5}$ \\ ${ }^{1}$ Performance Augmentation Lab, Oxford Brookes University, United Kingdom \\ ${ }^{2}$ Open University of the Netherlands \\ ${ }^{3}$ CCA Ltd, United Kingdom \\ ${ }^{4}$ Europlan UK Ltd, United Kingdom \\ ${ }^{5}$ VTT, Finland \\ wild@brookes.ac.uk, Roland.Klemke@ou.nl, paul.lefrere@cca- \\ research.co.uk, mikhail.fominykh@europlan-uk.eu, \\ Timo.Kuula@vtt.fi
}

Keywords: Augmented Reality, Wearable Technologies,

Technology Acceptance

\begin{abstract}
Augmented Reality and Wearables are the recent media and computing technologies, similar, but different from established technologies, even mobile computing and virtual reality. Numerous proposals for measuring technology acceptance exist, but have not been applied, nor fine-tuned to such new technology so far. Within this contribution, we enhance these existing instruments with the special needs required for measuring technology acceptance of Augmented Reality and Wearable Technologies and we validate the new instrument with participants from three pilot areas in industry, namely aviation, medicine, and space. Findings of such baseline indicate that respondents in these pilot areas generally enjoy and look forward to using these technologies, for being intuitive and easy to learn to use. The respondents currently do not receive much support, but like working with them without feeling addicted. The technologies are still seen as forerunner tools, with some fear of problems of integration with existing systems or vendor-lock. Privacy and security aspects surprisingly seem not to matter, possibly overshadowed by expected productivity increase, increase in precision, and better feedback on task completion. More participants have experience with AR than not, but only few on a regular basis.
\end{abstract}

\section{Introduction}

Technological innovations such as brain stimulation, simulations, sense making, augmented reality and virtual reality are making possible major changes in the following: the nature, depth and scope of human experiences; our capacity to re-experience and constructively reflect upon our own experiences; our ability to share actual experiences; our capacity to synthesize partly-false memories that combine fragments of

Preprint Version. Cite as: Wild, F., Klemke, R., Lefrere, P., Fominykh, M., \& Kuula, T. (2017, June). Technology Acceptance of Augmented Reality and Wearable Technologies. In International Conference on Immersive Learning (pp. 129-141). Springer, Cham. 
our direct experiences and synthesized third-party experiences. One indicator of this trend is recent work about people who lose or gain a core sense (see, for example, 'Notes on Blindness', http://www.notesonblindness.co.uk).

Sensory-focused work like that can be useful in assessing the social context, development and dynamics of changes in science and technology and thus being better able to empathise in some way with the initiators, developers, and prospective users of a given scientific or technological innovation, for example by providing ways to share and to communicate the experiences and feelings of people who are in need of a particular innovatory technology. A consequence of that empathetic approach is being able to extend how we identify and measure the degree of 'fit' between a technology and its users' needs and wants.

Numerous proposals for metrics for technology acceptance and behavioural intention to use were made in the past to help assess success of then-new information and communication technology before committing to and investing into its introduction [1-7]. The metrics and associated Technology Acceptance Models (TAMs) developed at a particular time reflect the insights, experiences and concerns of that time's expert communities, and the development and dynamics of the associated science, technology, society and culture. Technology innovations such as Virtual Reality (VR) and Augmented Reality (AR), can help to benchmark and predict success (and failure), but as acceptance is not independent of usage culture (think 'home office'), fashion trends (think 'themes'), and paradigm shifts (think 'mobile computing'), revisions had to be proposed over time.

The current third generation of AR does not only provide adaptation to location/viewpoint and not only links content with computer vision to physical objects [8], but provides immersive experience where human vision (and other senses) are manipulated in a way that very believable illusions seem to alter reality.

Wearable Technologies (WT), such as smart glasses, watches, or armbands, use embedded systems to fit accessories and garments with computing facilities. They play an important role as delivery devices for such immersive experience.

The combination of AR and WT is currently subjecting computing as we know it to further transformation - quite likely more than just a little disruption in usage culture, with nearly 1M AR Smart Glasses sold in 2015 and 10M expected for 2016 and mass markets of $>1$ B predicted for 2019-2023 [9, 10].

AR/WT solutions are not conventional software systems (like desktop software, web, or mobile application), but have different, non-standardised form factors as well as different user interfaces.

Within this contribution, we first investigate the suitability of the generic models acceptance models for benchmarking acceptance of AR/WT solutions, tending to the particularities of such emerging technologies.

Moreover, we investigate whether from the application context - not for home use for leisure or life, but in a workplace context in aviation, medicine, and space contexts - specific constraints on AR/WT acceptance can be identified. The three application areas are explored within the research project WEKIT. Each application area is represented in the project by an industrial partner company. 
We do so, because both, AR and WT as well as their application in these work contexts are emerging fields and remain widely unstudied: Existing studies look either into hardware [11], regardless of the application, or they are validation studies of effectiveness and efficiency of use [12], not acceptance.

The rest of this article is organized as follows. First, we describe the methodology for constructing scales, a two-stage approach of using experts to gather feedback on the scale items to select those that are on scope and that can be included in a questionnaire to be answered by participants to the three pilot areas of the WEKIT project (trials in aviation, medicine, and space). We report the results from the scale construction first to then report the results from the participants of the pilots that validate the applicability of the new scales. We also discuss what this 'baseline' benchmark means with respect to the introduction of AR and WT in an industrial context (and potential required interventions). An outlook on open problems and future plans for iterative measurements using the resulting model concludes the article.

\section{Methodology}

In order to build a model of what drives acceptance and use of technology in the context of maintenance and repair operations in aviation and space as well as training on operating procedures (of imaging equipment in the health sector), we collected items from existing technology acceptance models.

This included items from UTAUT, TAM-3, UTAUT-2, and TPB (see Section 3), as well as additional items from the generic literature on user experience (Ux). We enriched these items in focus groups with experts in technology as well as ergonomics to include also items specific to industry needs.

As Section 4 will report, this resulted in a pool of 91 statements, many of which belonging to groups of items, investigating the same construct, but asking for different aspects or using different phrases to express the same statement. The statements are formulated in a way so that they can be rated with a 7-point Likert scale, ranging from strongly disagree to strongly agree, including a neutral 'neither agree or disagree' in the middle. This pool of items to draw from would be too large to enquire with participants in the target groups directly, where a set of 15-20 items would be deemed appropriate.

In order to test reliability and measure internal validity of the constructs and items in the model, we asked 15 subject matter experts from a project consortium partnership to provide ratings for all items of the pool. With that, we measured the correlation (Pearson's r) across the responses with the sum scores of all items to assess that each item is actually measuring what we are interested in, testing for discriminatory power of the item [13]. The general assumption of this is that in total the chance for error is less likely than with a single item [13]. If responses to an item do not correlate with the sum scores of all items' responses, then it is very likely to not measure aspects of acceptance and use of technology, but rather something else. This analysis step allowed sorting out those items not correlating high with the sum score. 
Subsequently, we calculated the item-to-item correlations to identify further those items loading onto the same construct. If the correlation between two or more items is high, a single item (or a subset of the correlating items) can be selected. Then, Cronbach's $\alpha$ was measured to estimate interrater reliability, comparing the reliability for the full pool as well as the final subset selection.

Finally, the resulting questionnaire was validated with responses from 33 participants from the three industrial partner companies Lufttransport (Norway), EBIT (Italy), and ALTEC (Italy) in the areas of aviation, medicine, and space. A split half reliability test and the predictive quality of the items against measured behavioural intent over this pool of responses from end-user participants assess reliability and internal validity of the model. While the findings of technology acceptance of AR and WT of these 33 participants measured with this instrument may not be representative for the whole target group in the three industries, it still can serve as a reference for future investigations. Moreover, the sample size is large enough to assess reliability and internal validity and the results found indicate that this instrument can successfully be used to predict technology acceptance of AR and WT.

\section{$3 \quad$ Existing models of acceptance}

Venkatesh et al. compare eight models and integrate their constructs into the Unified Theory of Acceptance and Use of Technology (UTAUT), consisting of 31 items in four core determinants of intention and usage, namely Performance Expectancy (PE), Effort Expectancy (EE), Social Influence (SI), and Facilitating Conditions (FC), see Figure 1 [6]. Moreover, they identified four additional moderating variables, i.e., gender, age, experience, and voluntariness of use.

UTAUT thereby integrated constructs from the theory of reasoned action, the technology acceptance model, the motivational model, the theory of planned behaviour, a model of PC utilisation, social cognitive theory, and a combi-model. The model was validated and accounted for $70 \%$ of the variance in usage intention, outperforming the models it built on. Even though the results are very promising, the authors demand that "future research should be targeted at more fully developing and validating appropriate scales for each of the constructs" [6], while at the same time asking for "alternative measures of intention and behavior". They particularly stress the importance of further investigating the relation of individual and organisational technology acceptance (p.470) and propose to further align success factors relevant in these two social spheres.

One of the very established precursor models, is the Theory of Planned Behaviour (TPB) [14]. Key constructs in TPB are Attitude Towards Use (ATU), Subjective Norm (SN), and Perceived Behavioural Control (PBC). The model is still being applied in recent years. For example, Teo and Lee use it to explain about $40 \%$ of the variance in intention to use technology among student teachers [2], finding, however, $\mathrm{PBC}$ not to have any significant path from $\mathrm{PBC}$ to intention (and a rather small effect for Subjective Norm). 


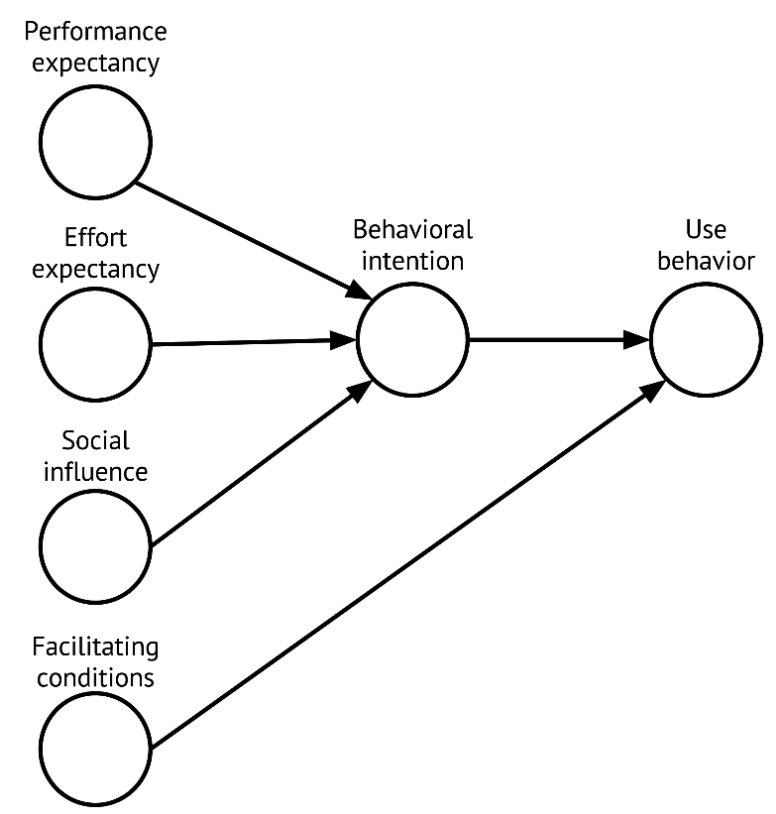

Fig. 1. Direct and indirect determinants of user acceptance and usage behaviour, redrawn from [6]

Venkatesh et al. propose an extension to UTAUT, adding Hedonic Motivation (HM), Price Value (PV), and Habit (HT) as constructs [1]. Price Value is especially important for consumer contexts, where costs define expectation of experience. Habit is automated, learned behaviour. Hedonic Motivation, also known as the "fun or pleasure derived from using a technology" [1], picks up on research into user experience [4]. Beyond the items proposed, various $\mathrm{uX}$ authors recommend additional constructs for assessing the experiential quality, in particular usability, utility, affective quality (AF), or aesthetic experience $[4,15,7]$.

Finally, Venkatesh and Bala propose the third version of the Technology Acceptance Model (TAM-3), comprising Subjective Norm, Image (IMG), Job Relevance, Output Quality, Result Demonstrability, Computer Self-Efficacy (CSE), Perceptions of External Control, and Computer Anxiety (CANX) to moderate Perceived Usefulness and Perceived Ease of Use that then drive Behavioural Intention (BI) and actual Use Behaviour [5].

\section{$4 \quad$ Item pool generation and reduction}

An expert panel was used to select items from the existing models introduced in Section 3 that were considered likely to be relevant for studying technology acceptance of AR and WT, casting the net widely. Moreover, the expert panel included additional items, resulting in a pool of 91 Likert statements plus six Use Behaviour (USE) questions, varying the delivery devices. 
The pool of 91 statements (and six different types of usage frequencies) were rated by the board of 15 subject matter experts using a 7-point Likert agreement scale each. The data table lists participant responses (rows) against items (columns), containing numeric value from 1 (strongly disagree) to 7 (strongly agree). For the first analysis step, sum scores for each row were calculated and each item vector was correlated with the sum score vector using Pearson's product moment coefficient $r$.

Results show that there are several items that do not correlate (directly or inversely) with the sum score (Fig. 2). There are 12 items in total correlating with the sum scores on a level higher than 0.7 , a total of 36 items on a level higher than 0.6 , and 45 items with a correlation value higher than 0.5 .

\section{Number of items for different Pearson's correlation coefficient thresholds}

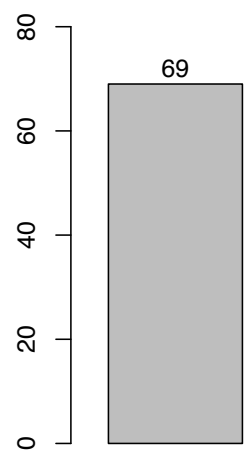

0.3

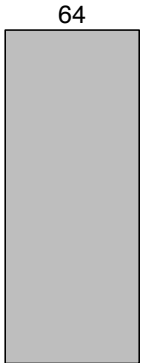

0.4

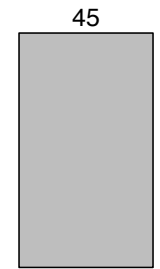

0.5

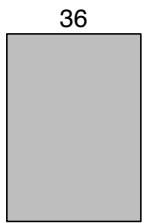

0.6

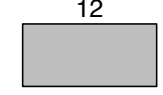

0.7

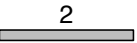

0.8

Fig. 2. Number of items for different correlation thresholds.

Since the sum scores are composed of all items, including items that may not directly measure what we intend to investigate, we decided to select a threshold of 0.6 of the absolute correlation as acceptable for identifying whether items are on scope. The sum scores indicate that the other constructs either measure something completely different or are not independent of other influences.

Next, we turned to item-to-item correlations and their groupings. The visual representation in Fig. 3. clearly indicates that there are groups of items that are related, as expected since we adopted several groups of items from the existing technology acceptance models. The figure displays the correlation matrix [16] of the items graphically, indicating the correlation value via the size (area) of the circles and additionally colour shade as well. The order of the items in the plot is determined using a hierarchical cluster analysis (hclust, package: stats) [17], so items close to each other along the diagonal are tend to correlate more highly.

The triangles visible along the diagonal and the rectangles further away from the diagonal of the figure indicate that there are groups of items belonging more closely together. This confirms already visually, that there are indeed groups of questions 
amongst the 36 items selected that may load on the same aspect. This potentially will allow picking just one of the items in each group (instead of posing all of them).

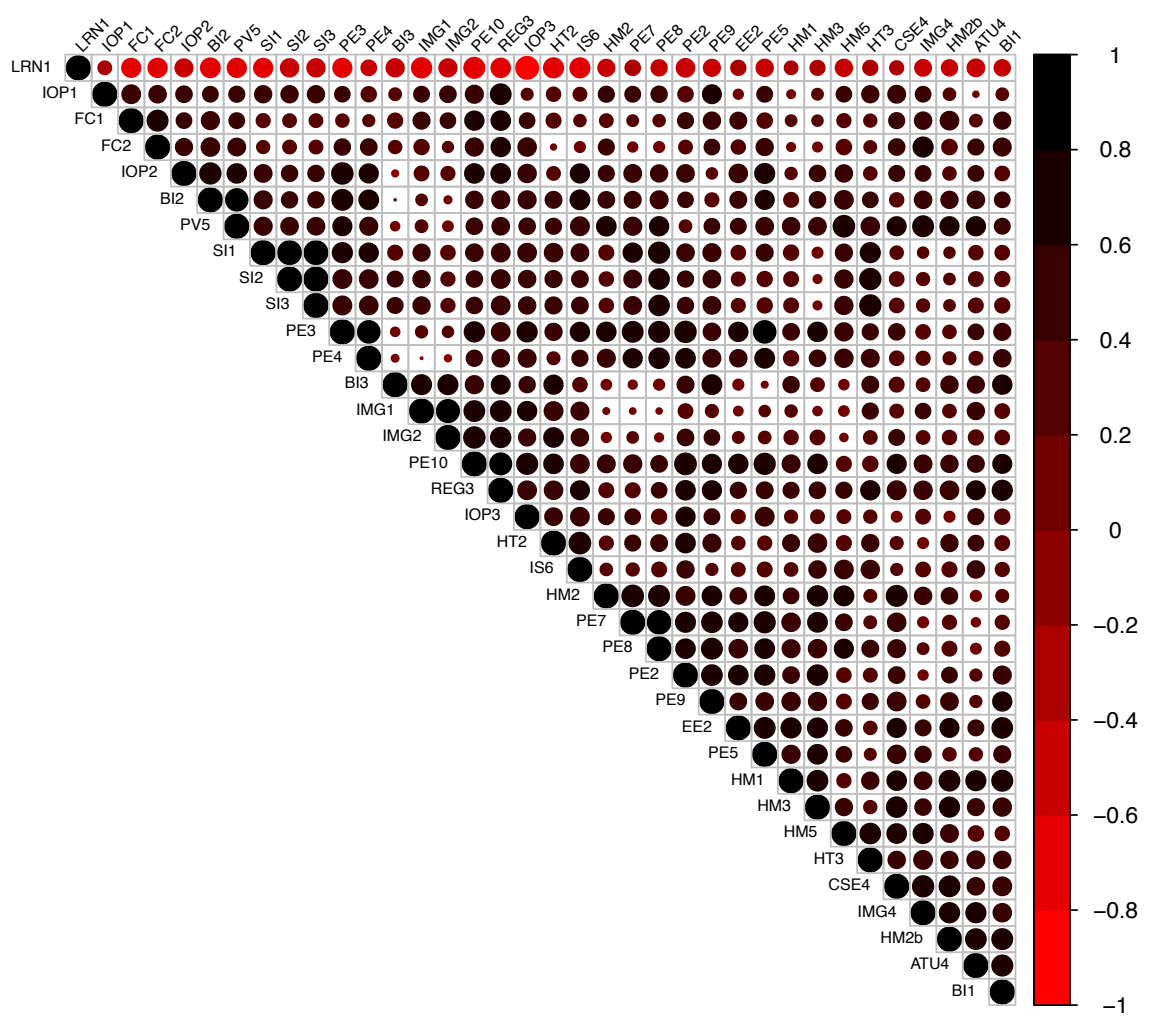

Fig. 3. Item to item correlations (selected 36 items)

\section{Selection of items}

Investigating the excluded items, i.e., the ones not in the 36-item selection (with correlations to the sum scores above 0.6 ), shows the following particularities.

Anxiety (group CANX) does not correlate with the sum scores. This may have to do with the selection of our test participants. This group of items is likely to be more relevant in an everyday use context and it may not be so relevant in a work context. Workers also may prefer management by objectives that are way within their capability. We can't separate whether anxiety would be personal or work related and this is better to explore qualitatively in an interview context, in which we can separate between personal use and work use (and the anxieties connected to it).

Questions about management support (such as DM1) are too early to ask, as in most contexts right now AR/WT are in prototype or exploratory use (if at all) and such question would need real exposure in daily routine. 
Questions about integration with legacy systems do not work. This is likely to have to do with competence of people asked, as system integration is not their job, nor within their knowledge. Similarly, the lack of exposure or exploratory use of AR/WT is a problem among this group of questions.

The question about appeal of the workplace to younger people is out of place: respondents may not know this. Questions about content and content experience (in dropped items in IOP) could not be answered. Maybe end-users do not see this separation between content and system as we do.

The lack of correlation with sum scores of questions on privacy may be a result of lack of exposure (or infrequent daily use). Questions also do not differentiate by target group of data (and their level of exposure), this would have to be further specified.

The target group cannot answer statements on value for money.

For both the full pool as well as the selected 36 items, the standardized Cronbach's $\alpha$, as a measure of internal consistency, is similarly high ( 0.96 for the full pool, 0.97 for the 36 items).

Analysis of the 36 included items and their item groups finds that several items correlate highly within their group and a choice can be made for the phrasing with more clarity or for the aesthetically more pleasing formulation (see Table 1).

Table 1. Analysis of item groups (selected items shaded in black). Item texts are listed in Table 2 (if selected) and in the references in Section 3 (if not selected).

\begin{tabular}{|c|c|c|}
\hline ITEM & COR & ANALYSIS \\
\hline ATU4 & 0.63 & Better question than alternatives (A1, AF1): future oriented. \\
\hline BI1 & 0.71 & \multirow{3}{*}{$\begin{array}{l}\text { Expected to group, but inter item correlations }(0.4,0.6,0.01) \text { is } \\
\text { not very strong. Preference for BI } 2 \text { over } \mathrm{BI} 1 / \mathrm{BI} 3 \text {, because it is } \\
\text { not dependant on current use of AR/WT. }\end{array}$} \\
\hline $\mathrm{BI} 2$ & 0.69 & \\
\hline $\mathrm{BI} 3$ & 0.6 & \\
\hline CSE4 & 0.71 & Covers the other three CSE items. \\
\hline EE2 & 0.61 & $\begin{array}{l}\text { Works best amongst this group of EE items. More technical than } \\
\text { the other questions - good in our technology context. }\end{array}$ \\
\hline $\mathrm{FC} 1$ & 0.65 & \multirow{2}{*}{$\begin{array}{l}\text { FC1 and FC2 work well (they correlate with } 0.74 \text {, keep FC1 as it } \\
\text { is the more broadly formulated one). }\end{array}$} \\
\hline FC2 & 0.62 & \\
\hline HM1 & 0.63 & \multirow{4}{*}{$\begin{array}{l}\text { Expected that we can only ask one of these HM items - they are } \\
\text { very similar. }\end{array}$} \\
\hline HM2 & 0.61 & \\
\hline HM2b & 0.67 & \\
\hline HM3 & 0.63 & \\
\hline HM5 & 0.67 & Badly phrased, drop. \\
\hline HT2 & 0.7 & \multirow{2}{*}{$\begin{array}{l}\text { Two of the four HT items correlate with sum scores. HT2 and } \\
\text { HT3 correlate with } 0.5 \text {, but HT2 is better formulated. }\end{array}$} \\
\hline HT3 & 0.72 & \\
\hline IMG1 & 0.65 & \multirow{3}{*}{$\begin{array}{l}\text { Three of the four IMG items correlate higher with the sum score. } \\
\text { Expect two more to drop out with group analysis: IMG1 vs. } \\
\text { IMG2: } 0.91 \text {, so keep IMG1. }\end{array}$} \\
\hline IMG2 & 0.62 & \\
\hline IMG4 & 0.69 & \\
\hline IOP1 & 0.66 & \multirow{3}{*}{$\begin{array}{l}\text { 3/10 IOP items correlate highly with sum scores. Questions on } \\
\text { existing integration and on content / content experience cannot be } \\
\text { answered. IOP } 1,2,3 \text { do not correlate }(0.45,0.23,0.57) \text {. Drop }\end{array}$} \\
\hline IOP2 & 0.64 & \\
\hline IOP3 & 0.68 & \\
\hline
\end{tabular}




\begin{tabular}{|c|c|c|}
\hline \multirow{3}{*}{$\begin{array}{l}\text { IS6 } \\
\text { LRN1 }\end{array}$} & \multicolumn{2}{|r|}{ IOP1, as "interoperability" is a difficult word. } \\
\hline & 0.69 & Only item left in this group. \\
\hline & -0.78 & Reverse item. \\
\hline PE2 & 0.71 & Very close, pick PE4 as it is more different from the other PE \\
\hline PE3 & 0.74 & items. \\
\hline PE4 & 0.62 & \\
\hline PE5 & 0.69 & These are novel, AR/WT functionality related questions. The \\
\hline PE7 & 0.6 & task completion questions can be grouped. Reduce error and \\
\hline PE8 & 0.65 & increase precision express the same. \\
\hline PE9 & 0.73 & \\
\hline PE10 & 0.87 & \\
\hline PV5 & 0.74 & Out of context: interpretation impossible w/o other PV items. \\
\hline REG3 & 0.87 & Should have been an inverse item, but isn't, so: drop. \\
\hline SI1 & 0.71 & Similar, picked one of the three well loading items. \\
\hline SI2 & 0.7 & \\
\hline SI3 & 0.7 & \\
\hline
\end{tabular}

\section{Final questionnaire}

The final set of statements contained 20 items (Table 2).

Table 2. Final metric scale

\begin{tabular}{|c|c|}
\hline CODE & STATEMENT \\
\hline ATU4 & I look forward to those aspects of my job that require me to use AR \& WT. \\
\hline CSE4 & $\begin{array}{l}\text { I could complete a job, if I had used similar technologies before this one to } \\
\text { do the same job. }\end{array}$ \\
\hline EE2 & My interaction with AR \& WT is clear and understandable. \\
\hline $\mathrm{FC1}$ & I have the resources necessary to use AR \& WT. \\
\hline HM2b & I like working with AR \& WT. \\
\hline HT2 & I am addicted to using AR \& WT. \\
\hline IMG1 & $\begin{array}{l}\text { People in my organization who use AR \& WT have more prestige than } \\
\text { those who do not. }\end{array}$ \\
\hline IMG4 & $\begin{array}{l}\text { I use AR \& WT solutions, because I want to be a forerunner in technology } \\
\text { exploitation. }\end{array}$ \\
\hline IOP1 & Interoperability is important for AR \& WT. \\
\hline IOP2 & I am worried about vendor lock in with AR \& WT. \\
\hline IOP3 & Integration costs of AR \& WT with other software systems in use are high. \\
\hline IS6 & I would find it useful if my friends knew where I am and what I am doing. \\
\hline LRN1 & $\begin{array}{l}\text { Learning curve for AR \& WT is too high compared with the value they } \\
\text { would offer. }\end{array}$ \\
\hline PE10 & With AR \& WT, I immediately know when a task is finished. \\
\hline PE4 & Using AR \& WT increases my productivity. \\
\hline
\end{tabular}




\begin{tabular}{ll}
\hline PE8 & AR \& WT increase precision of tasks. \\
\hline SI1 & People who are important to me think that I should use AR \& WT. \\
\hline BI2 & I will always try to use AR \& WT in my daily life. \\
\hline UF1 & Please choose your usage frequency of AR/WT \\
\hline
\end{tabular}

\section{Current level of Technology Acceptance}

The final resulting questionnaire now allowed us to administer another survey with participants from the pilot companies, which allows validating whether the metric scale successfully predicts technology acceptance. Even though not necessarily representative of the three industries (qua its small and non-representative sample size), it still provides a first reference for what drives technology acceptance, use, and all the other success factors.

We ran the questionnaire with the aim to draw an equal share of participants for each pilot area WEKIT is looking at (about 10 each). Additional people across the project consortium contributed. Most of our participants are male and aged 25-44, with only a few being younger or older. Respondents come mainly from the space industry and the educational field, with additional participants classifying themselves as from transportation, R\&D, manufacturing, or medicine. Participants added maintenance, media, IT consulting, and telecommunication service provider to the list of industries offered. Within these organisations participants are mainly end-users or researchers, with some participants being managers, developers, or trainers.

The findings for these 33 are presented below in Fig. 4. The respondents generally look forward to using AR/WT (ATU4) or are neutral about it and plan to use AR/WT in their daily life (BI2). They are rather neutral about learnability of AR/WT for being similar to existing technologies (CSE4), but agree that their interaction with AR/WT is generally clear and understandable (EE2).

Participants do not necessarily have the resources available (FC1) to use AR/WT (some do, some don't), but the majority likes working with AR/WT (HM2b) without feeling addicted to it (HT2). They don't see AR/WT as prestigious tools (IMG1) but rather a tool for forerunners (IMG4). Interoperability is seen as a highly relevant issue (IOP1) and participants are slightly worried about vendor lock-ins (IOP2). They fear high integration costs for AR/WT solutions (IOP3).

Participants are rather neutral about privacy and security aspects, i.e. the use of AR/WT for informing others about current activity or location (IS6). In addition, they are neutral about the learning curve needed to adopt AR/WT (LRN1).

With respect to performance expectancy, participants are slightly inclined to believe in an increase of productivity (PE4), an increase of precision (PE8), and the advantage of feedback on task completion (PE10). Participants are rather neutral about social influence of other people on the use of AR/WT (SI1).

The majority of participants has no experience in the use (UF1) of AR/WT (never: $\mathrm{n}=14$ ), some use AR/WT rarely (once/month: $\mathrm{n}=7$; once/two weeks: $\mathrm{n}=6$ ). Only a few people use AR/WT on a regular basis (daily: $n=1$; several times a week: $n=5$ ). 


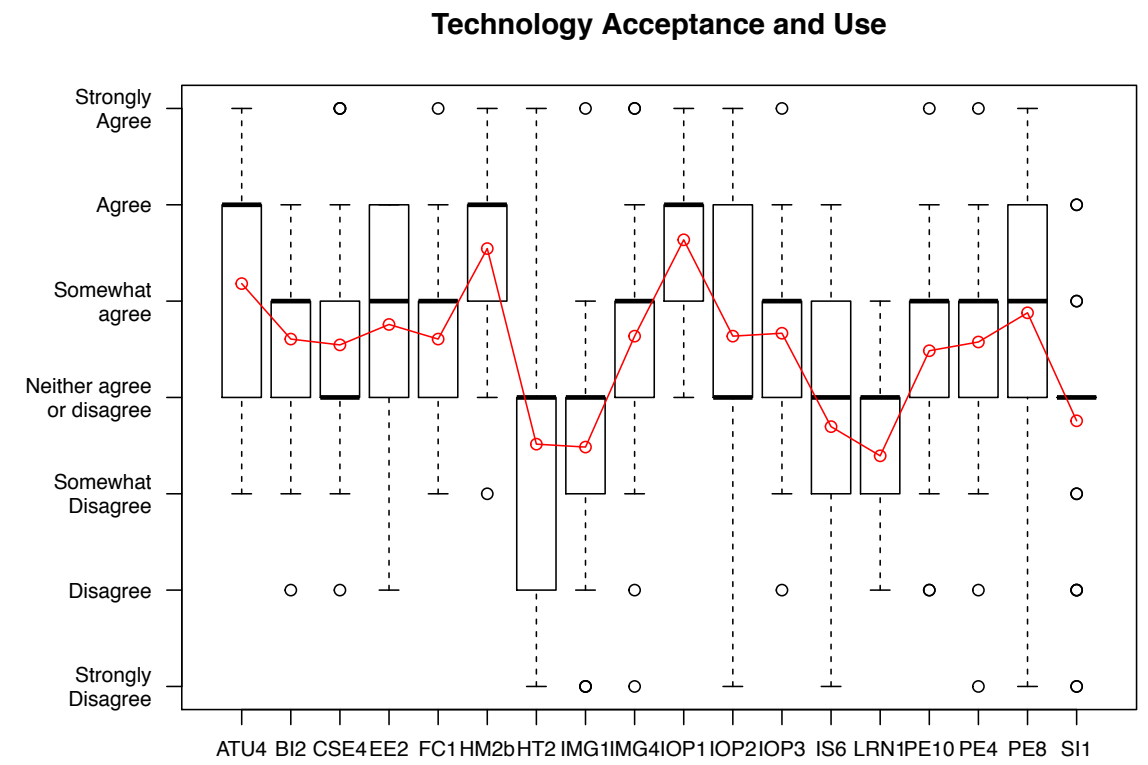

Fig. 4. Variance in the validation sample

We tested the reliability of the developed questionnaire with a split half reliability test [13]. This means calculating the correlation between the sum scores of oddcolumn items versus the sum scores of even-column items, resulting in a Pearson's $r$ value of 0.77 . Since 'limiting' the number of items for the halves to half the full set, the underestimation can be corrected with the Spearman and Brown formula: rs = $2 * \mathrm{rs} 1, \mathrm{~s} 2 /(1+\mathrm{rs} 1, \mathrm{~s} 2)$. This results in rs of 0.87 , which is above the recommended value of 0.80 [13]. The standardised Cronbach's $\alpha$ is 0.86 (same with the raw $\alpha$ ).

Testing the predictive quality of the sum scores against BI2, the behavioural intention to use shows a correlation effect of 0.6075 (Pearson's r), which is highly significant with a p-value below 0.001 . This shows that the developed adapted metric scale can actually be used to predict technology acceptance (measured via the behavioural intent) through the core determinants enquired.

\section{Conclusion}

Within this contribution, we have extended and applied a metric scale to assess technology acceptance, including key factors determining success. In particular and beyond existing models, we have added constructs and items for interoperability, learnability, and privacy, as these items deserve special attention in this current phase of emergence of an AR/WT market. We have validated the adapted and extended metric scale in two stages, first with experts and then with 33 end-user participants. Results indicate that the adapted and extended metric scale can successfully be used to assess technology acceptance of AR and WT. 
In the industries screened, it is clear that specific attention has to be paid to equipping users with the resources needed, in particular with the devices. Device management will be an issue, also for managing update and upgrade procedures. Integration with legacy systems is of big concern, so in the introduction of AR/WT, interfaces have to be created ensuring that any new solution fits seamlessly in into the existing pool of hard- and software.

More than half of the participants in this sample did not have prior exposure to AR and WT. Studying the difference between these users with direct experience to those having none could possibly provide valuable insights about, for example, expectations or potential misconceptions.

It is important to ensure solutions meet expectations with respect to hedonic quality and performance gains. Hopes are high that an increase in productivity, precision, live feedback will be delivered by solutions that are fun to use. If these expectations are not fulfilled, acceptance will suffer. This clearly demands thorough user experience and usability/utility testing. For an overview on the according methodology see [18].

We found a lack of social influence and, at the same time, expectations about AR/WT being used by forerunners. This indicates potential for supporting the introduction with social communities, with key personnel leading by example. We expect that with more widespread use of AR/WT peer pressure will rise.

The lack of concern about privacy is surprising, indicating lack of exposure. To avoid legal consequences to arise ex post, we recommend elaborating individual policies for privacy and data security in joint consultation with providers, management, and employee representatives.

Acknowledgement. This work was supported by the European Commission under the Horizon 2020 Programme (H2020), as part of WEKIT (grant agreement no. 687669).

\section{References}

1. Venkatesh V., Thong J.Y.L., Xu X.: Consumer acceptance and use of information technology: extending the unified theory of acceptance and use of technology. MIS Q 36 (1), 157-178 (2012)

2. Teo T., Beng Lee C.: Explaining the intention to use technology among student teachers: An application of the Theory of Planned Behavior (TPB). Campus-Wide Information Systems 27 (2), 60-67 (2010)

3. Schulze K., Kr H., \#246, mker (2010) A framework to measure user experience of interactive online products. Paper presented at the Proceedings of the 7 th International Conference on Methods and Techniques in Behavioral Research, Eindhoven, The Netherlands,

4. Law E.L.-C., Roto V., Hassenzahl M., Vermeeren A.P.O.S., Kort J. (2009) Understanding, scoping and defining user experience: a survey approach. Paper presented at the Proceedings of the SIGCHI Conference on Human Factors in Computing Systems, Boston, MA, USA,

5. Venkatesh V., Bala H.: Technology Acceptance Model 3 and a Research Agenda on Interventions. Decision Sciences 39 (2), 273-315 (2008) 
6. Venkatesh V., Morris M.G., Davis G.B., Davis F.D.: User acceptance of information technology: toward a unified view. MIS Q 27 (3), 425-478 (2003)

7. Law E.L.-C., Hassenzahl M., Karapanos E., Obrist M., Roto V. (2014) Tracing links between UX frameworks and design practices: dual carriageway. Paper presented at the Proceedings of HCI Korea, Seoul, Republic of Korea,

8. Langlotz T., Grubert J., Grasset R.: Augmented reality browsers: essential products or only gadgets? Commun ACM 56 (11), 34-36 (2013)

9. Yano-Research: Global Wearable Device Market: Key Research Findings 2016. Yano Research Institute Ltd., May 16, (2016), https://www.yanoresearch.com/press/press.php/001535

10. Inbar O.: Opening Keynote Augmented World Expo 2016. Augmented World Expo (2016), https://youtu.be/dRP8eJ2_8xc?t=5m20s

11. Rauschnabel P.A., Brem A., Ivens B.S.: Who will buy smart glasses? Empirical results of two pre-market-entry studies on the role of personality in individual awareness and intended adoption of Google Glass wearables. Computers in Human Behavior 49, 635-647 (2015)

12. Scavo G., Wild F., Scott P.: The GhostHands UX: telementoring with hands-on augmented reality instruction. In: Volume 19: Workshop Proceedings of the 11th International Conference on Intelligent Environments. Ambient Intelligence and Smart Environments, pp. 236-243. (2015)

13. Diekmann A.: Empirische Sozialforschung: Grundlagen, Methoden, Anwendungen. Vollst. überarb. und erw. Neuausg., 18. Aufl. $=$ [1. Aufl. der Neuausg.] edn. RowohltTaschenbuch-Verl., Reinbek bei Hamburg (2007)

14. Ajzen I.: The theory of planned behavior. Organizational Behavior and Human Decision Processes 50 (2), 179-211 (1991)

15. Olsson T., Lagerstam E., Kärkkäinen T., Väänänen-Vainio-Mattila K.: Expected user experience of mobile augmented reality services: a user study in the context of shopping centres. Personal and Ubiquitous Computing 17 (2), 287-304 (2013)

16. Wei T., Simko V. (2016) corrplot: Visualization of a Correlation Ma-trix. https://cran.rproject.org/web/packages/corrplot/index.html

17. R-Development-Core-Team: R: A Language and Environment for Statistical Computing. the R Foundation for Statistical Computing, Vienna, Austria (2016), http://www.Rproject.org/

18. Law E.L.-C., Wild F.: A Multidimensional Evaluation Framework for Personal Learning Environments. In: Kroop S, Mikroyannidis A, Wolpers M (eds.) Responsive Open Learning Environments: Outcomes of Research from the ROLE Project. pp. 49-77. Springer International Publishing, Cham (2015) 